Optimization of the etch-and-rinse technique : New pÿperspectives to improve resin dentin bonding and hybrid layer integrity by reducing residual water using dimethyl sulfoxide pretreatments

Stape, Thiago Henrique Scarabello

2018-07

Stape , T H S , Tjäderhane , L , Abuna , G , Sinhoreti , M A C , Martins , L R M \& Tezvergil-Mutluay, A 2018 , ' Optimization of the etch-and-rinse technique : New pÿperspectives to improve resin dentin bonding and hybrid layer integrity by reducing residual water using dimethyl sulfoxide pretreatments ', Dental Materials, vol. 34 , no. 7 , pp. 967-977 . https://doi.org/10.1016/j.dental.2018.03.010

http://hdl.handle.net/10138/302394

https://doi.org/10.1016/j.dental.2018.03.010

publishedVersion

Downloaded from Helda, University of Helsinki institutional repository.

This is an electronic reprint of the original article.

This reprint may differ from the original in pagination and typographic detail.

Please cite the original version. 


\title{
Optimization of the etch-and-rinse technique: New perspectives to improve resin-dentin bonding and hybrid layer integrity by reducing residual water using dimethyl sulfoxide pretreatments
}

\author{
Thiago Henrique Scarabello Stape ${ }^{a, b, *}$, Leo Tjäderhane ${ }^{c, d, e}$, Gabriel Abuna ${ }^{f}$, \\ Mário Alexandre Coelho Sinhoreti ${ }^{f}$, Luís Roberto Marcondes Martins ${ }^{9}$, \\ Arzu Tezuergil-Mutluay ${ }^{a, b}$ \\ a Department of Restorative Dentistry and Cariology, Adhesive Dentistry Research Group, Institute of Dentistry, \\ University of Turku, Turku, Finland \\ $\mathrm{b}$ Turku University Hospital, TYKS, University of Turku, Turku, Finland \\ c Department of Oral and Maxillofacial Diseases, University of Helsinki, Helsinki, Finland \\ d Helsinki University Hospital, Helsinki, Finland \\ e Research Unit of Oral Health Sciences, and Medical Research Center Oulu (MRC Oulu), Oulu University Hospital \\ and University of Oulu, Oulu, Finland \\ ${ }^{f}$ Piracicaba Dental School, University of Campinas, Department of Restorative Dentistry, Dental Materials Area, \\ Piracicaba, SP, Brazil \\ g Piracicaba Dental School, University of Campinas, Department of Restorative Dentistry, Piracicaba, SP, Brazil
}

\section{A R T I C L E I N F O}

\section{Article history:}

Received 25 August 2017

Received in revised form

30 December 2017

Accepted 23 March 2018

\section{Keywords:}

Dry-bonding

Wet-bonding

Bond strength

Micropermeability

Nanoleakage

Dentin

\begin{abstract}
A B S T R A C T
Objective. To determine whether bonding effectiveness and hybrid layer integrity on acidetched dehydrated dentin would be comparable to the conventional wet-bonding technique through new dentin biomodification approaches using dimethyl sulfoxide (DMSO).

Methods. Etched dentin surfaces from extracted sound molars were randomly bonded in wet or dry conditions (30 s air drying) with $\mathrm{DMSO} /$ ethanol or $\mathrm{DMSO} / \mathrm{H}_{2} \mathrm{O}$ as pretreatments using a simplified (Scotchbond Universal Adhesive, 3M ESPE: SU) and a multi-step (Adper Scotchbond Multi-Purpose, 3M ESPE: SBMP) etch-and-rinse adhesives. Untreated dentin surfaces served as control. Bonded teeth $(n=8)$ were stored in distilled water for $24 \mathrm{~h}$ and sectioned into resin-dentin beams $\left(0.8 \mathrm{~mm}^{2}\right)$ for microtensile bond strength test and quantitative interfacial nanoleakage analysis $(n=8)$ under SEM. Additional teeth $(n=2)$ were prepared for micropermeability assessment by CFLSM under simulated pulpar pressure $\left(20 \mathrm{~cm} \mathrm{H}_{2} \mathrm{O}\right)$ using $5 \mathrm{mM}$ fluorescein as a tracer. Microtensile data was analyzed by 3-way ANOVA followed by Tukey Test and nanoleakage by Kruskal-Wallis and Dunn-Bonferroni multiple comparison test $(\alpha=0.05)$.
\end{abstract}

\footnotetext{
* Corresponding author at: Institute of Dentistry, University of Turku, Lemminkaisenkatu 2, Turku, 20520, Finland.

E-mail addresses: thscst@utu.fi (T.H.S. Stape), leo.tjaderhane@oulu.fi (L. Tjäderhane), abuna@outlook.com (G. Abuna), sinhoreti@fop.unicamp.br (M.A.C. Sinhoreti), martins@fop.unicamp.br (L.R.M. Martins), arztez@utu.fi (A. Tezvergil-Mutluay). https://doi.org/10.1016/j.dental.2018.03.010

0109-5641/@ 2018 The Academy of Dental Materials. Published by Elsevier Inc. All rights reserved.
} 
DMSO

Ethanol

Dentin

Adhesives
Results. While dry-bonding of SBMP produced significantly lower bond strengths than wet-bonding $(p<0.05), \mathrm{DMSO} / \mathrm{H}_{2} \mathrm{O}$ and DMSO/ethanol produced significantly higher bond strengths for SBMP irrespective of dentin condition $(p<0.05)$. SU presented significantly higher nanoleakage levels $(p<0.05)$ and micropermeability than SBMP. Improvement in hybrid layer integrity occurred for SBMP and SU for both pretreatments, albeit most pronouncedly for DMSO/ethanol regardless of dentin moisture.

Conclusion. DMSO pretreatments may be used as a new suitable strategy to improve bonding of water-based adhesives to demineralized air-dried dentin beyond conventional wetbonding. Less porous resin-dentin interfaces with higher bond strengths on air-dried etched dentin were achieved; nonetheless, overall efficiency varied according to DMSO's co-solvent and adhesive type.

Clinical significance. DMSO pretreatments permit etched dentin to be air-dried before hybridization facilitating residual water removal and thus improving bonding effectiveness. This challenges the current paradigm of wet-bonding requirement for the etch-and-rinse approach creating new possibilities to enhance the clinical longevity of resin-dentin interfaces.

(c) 2018 The Academy of Dental Materials. Published by Elsevier Inc. All rights reserved.

\section{Introduction}

Despite the evolution in adhesive dentistry over the past decades [1-3], degradation of tooth-bonded interfaces [2] still contributes to the reduced long-term clinical success of adhesive restorations [4-6]. Currently, resin-dentin bonding relies on effective adhesive penetration into demineralized collagen matrix for proper hybrid layer formation [2,7]. The hybrid layer is characterized by the creation of complex collagenresin biopolymers aiming to provide a continuous and stable link between the bulk adhesive and dentin substrate [1,2]. In face of the limitations of most current clinically-feasible bonding protocols and inherent drawbacks of the etch-and-rinse approach per se [1] an ideal resin-enveloped collagen scaffold is unlikely to be produced in a consistent manner. In dentin hybridization, adhesive infiltration is far from perfect $[1,8,9]$ resulting in poorly formed hybrid layers. Replacement of all $70 \mathrm{vol} \%$ residual water in etched-dentin [1] with monomers is hardly achieved. For this reason, the hybrid layer may be considered as the weak link in resin-dentin bonds [10,11]. All in all, improvements in resin-dentin bonding effectiveness using simple time-efficient bonding protocols [9,11,12] aiming to eliminate the presence of residual water during dentin hybridization are still required.

The etch-and-rinse dentin bonding approach still relies on traditional wet-bonding technique to couple relatively hydrophilic adhesives to the hydrated dentin substrate in clinically relevant protocols. A partially wet dentin substrate has been consensually advocated to maintain the demineralized collagen matrix expanded for proper resin infiltration by relatively hydrophilic monomers [13]. Nevertheless, management of adequate moisture is not easily accomplished, and either excess or lack of dentin moisture may compromise resin-dentin bonding [14-16]. Although adequate resin-dentin bonding is usually immediately achieved, reduced bonding efficiency occurs with time [2,4-7]. Such lack of durability may be partly attributed to the involvement of excess residual water with poorly formed hybrid layers $[17,18]$ for water: (i) causes phase separation of adhesive components [19] during hybridization, (ii) accelerates hydrolysis of polymers containing ester linkages [20] on the long run; and (iii) allows endogenous host-derived collagen-hydrolytic enzymes (i.e. matrix metalloproteinases and cathepsins) to degrade demineralized collagen. In this sense, creation of less porous hybrid layers with reduced water content and affinity could indeed improve dentin bonding.

The main problem lies on how to remove excess water without compromising resin-dentin interaction. Previous attempts to remove excess residual water from the bonded interface using dry-bonding protocols have generally produced inadequate resin-dentin interfaces [14]. Collapse of air-dried collagen drastically reduces the interfibrillar spaces that serve as diffusion paths for resin infiltration [13] and produces a surface more resistant to wetting [21]. To overcome the drawbacks of excessive air-drying, the ethanol wet-bonding technique was proposed to gradually replace free water from the dentin substrate before resin bonding. Even though encouraging in vitro results have been presented $[1,13]$, the technique proved to be clinically unfeasible and highly technique sensitive [1] due to the extra bonding steps and higher likelihood of demineralized collagen matrix collapse after ethanol evaporation. Recently, dimethyl sulfoxide (DMSO) has been introduced as a new potential solvent to be used in adhesive dentistry [8,22]. DMSO [ $\left.\left(\mathrm{CH}_{3}\right)_{2} \mathrm{SO}\right]$ is a polar aprotic solvent that dissolves both polar and non-polar compounds. It is a polyfunctional molecule, with a highly polar $\mathrm{S}=\mathrm{O}$ group and two hydrophobic methyl groups, fully miscible in most solvents and monomers used in adhesive dentistry [23]. DMSO is perhaps the best currently known penetration enhancer for medical purposes [24] with the ability to dissociate the highly crosslinked collagen into a sparser network of apparent fibrils [25] concentration dependently. In addition, dissociation of water self-associative tendency by DMSO [26] improves wettability of demineralized dentin $[27,28]$, monomer diffusion into the collagen matrix [8] and concomitantly re-expands collapsed collagen to a fairly modest level [28]. 
The possibility of combining DMSO and ethanol to displace and reduce water from the bonded interface and improve resin-dentin interaction brings up unexplored possibilities regarding resin-dentin bonding to dry dentin. The aim of this study was to examine the central hypothesis that biomodification of the dentin substrate produced by DMSO mixtures would permit adequate resin bonding to dehydrated demineralized dentin. Therefore, the effect of new dentin bonding approaches, consisting of $\mathrm{DMSO} / \mathrm{H}_{2} \mathrm{O}$ and DMSO/ethanol pretreatments applied onto wet and extensively air-dry dentin, on the bond strength micropermeability and nanoleakage of three-step and two-step etch-and-rinse adhesives was investigated. The null hypotheses to be tested were that irrespective of dentin moisture, pretreatments containing DMSO would have no effect on (i) bond strength and (ii) and hybrid layer integrity.

\section{Material and methods}

\subsection{Tooth preparation and bonding procedures}

Sound human third molars were extracted for surgical reasons under an informed consent from the patients (age: 18-24 years) reviewed and approved by the Ethics Committee of the University of Oulu, Finland (19/2006). The teeth were cleaned and stored in $0.5 \%$ chloramine-T at $4{ }^{\circ} \mathrm{C}$ for one week, rinsed and stored in distilled water $(\mathrm{pH}$ 7.1) until use for no more than 3 months at $4{ }^{\circ} \mathrm{C}$. Teeth were sectioned $1 \mathrm{~mm}$ beneath the cemento-enamel junction using diamond wafering blades in a slow-speed saw (Isomet 1000 Precision Saw, Buehler, Lake Bluff, IL, USA) and occlusal enamel was subsequently removed with a parallel cut to expose flat midcoronal dentin surfaces. Bonding surfaces were standardized using P320 silicon carbide paper (CarbiMet, Buehler) for $60 \mathrm{~s}$ under water cooling. Teeth were randomly divided into 12 groups $(n=8)$ following a study design composed of three studying factors: (i) "adhesive system" in two levels composed by a three-step etch-and-rinse (Adper Scotchbond Multi-Purpose: SBMP, 3M ESPE, St Paul, MN, USA) and a universal adhesive in etch-and-rinse mode (Scotchbond Universal Adhesive: SU, 3M ESPE); (ii) "dentin moisture" in two levels using the dryand wet-bonding approach; and (iii) "dentin pretreatment" in three levels consisted of no treatment following manufacturer instructions and application of two DMSO solutions for $60 \mathrm{~s}$ after dentin etching. The $50 \%(\mathrm{v} / \mathrm{v})$ solutions were prepared immediately before use mixing DMSO (Dimethyl Sulfoxide, Sigma-Aldrich, St Louis, MO, USA) in distilled water or ethanol (Ethanol, Sigma-Aldrich). The rationale for using $50 \%(\mathrm{v} / \mathrm{v})$ DMSO was based on previous studies that employed the same concentration, albeit only in aqueous solutions, reporting significant improvements in resin-dentin interactions under wet conditions [29-31]. Table 1 displays the mode of application, components and batch number of the adhesives. For the wet-bonding protocols, blot-drying with paper filters was carefully performed leaving the dentin surface visibly moist. Dry-bonding was performed by blot-drying until no signs of visible moisture were detected followed by continuous air blast using a 3-way syringe at a distance of $10 \mathrm{~cm}$ for $30 \mathrm{~s}$. Dentin pretreatments consisted of active application of $50 \mu \mathrm{L}$
DMSO/ $\mathrm{H}_{2} \mathrm{O}$ or DMSO/ethanol solutions on etched-dentin followed by blot drying until paper filters were no longer able to remove liquids from the bonding surface by capillarity. Adhesive systems were applied with slight rubbing action onto the demineralized dentin surface totaling $20 \mathrm{~s}$ for SU and $10 \mathrm{~s}$ for each of SBMP Primer and Bond with manual pressure of approximately $4.0 \mathrm{~g} \pm 1.6$ [32]. Adhesive procedures were carried out in a controlled environment with a temperature of $24^{\circ} \mathrm{C}$ and a relative humidity of $45-55 \%$. Resin composite restorations (Z250, shade A2, 3 M ESPE) were built on top of the bonded dentin surfaces in four 1-mm increments that were individually light-cured for $40 \mathrm{~s}$. Light curing of all resin materials was performed using a LED device (Bluephase 20i, Ivoclare Vivadent, Schaan, Liechtenstein) that delivered $1100 \mathrm{~mW} / \mathrm{cm}^{2}$.

\subsection{Microtensile bond strength ( $\mu \mathrm{TBS})$ test}

After storage in distilled water at $37^{\circ} \mathrm{C}$ for $24 \mathrm{~h}$, the restored crown segments were longitudinally sectioned into $0.9-\mathrm{mm}$ slabs across the adhesive interface with a water-cooled diamond wafering blade. The slabs were further sectioned into resin-dentin beams with cross-sectional area of approximately $0.8 \mathrm{~mm}^{2}$ in accordance with the "non-trimming" technique [33]. Beams were individually attached to a microtensile fixture (OD03d, ODEME Biotechnology, Luzerna, SC, Brazil) with a cyanoacrylate adhesive (Zapit, Dental Ventures of America, Corona, CA, USA) and submitted to the test (DL2000, EMIC, São José dos Pinhais, PR, Brazil) in tension, at a crosshead speed of $0.5 \mathrm{~mm} / \mathrm{min}$ until failure. The cross-sectional area of each beams was measured with a digital caliper (Absolute Digimatic, Mitutoyo, Tokyo, Japan) to the nearest $0.01 \mathrm{~mm}$ to calculate the actual bond strength (MPa). The failure pattern modes were evaluated at $40 \times$ magnification under a stereomicroscope (Leica M60, Leica Microsystems, Heidelberg, Germany) and classified as cohesive (C) when exclusively within dentin or resin composite, adhesive (A) when failure occurred at the dentin/resin interface, or mixed (M) when two modes of failure happened simultaneously.

\subsection{Assessment of micropermeability with confocal laser scanning microscopy (CLSM)}

Further teeth for each group $(n=2)$ were prepared for hybrid layer micropermeability analysis under simulated pulpar pressure. The pulpal tissue was carefully removed with tweezers, after sectioning off the roots $1 \mathrm{~mm}$ below the cemento-enamel junction. Bonding procedures were performed as previously described except that the adhesives were doped with $0.1 \mathrm{wt} \%$ Rhodamine B (Sigma-Aldricht, Louis, MO, USA) [34]. The fluorescent dye used to trace the waterfilled spaces along the bonded interface was a solution of Sodium Fluorescein $5 \mathrm{mM}$ (Sodium Fluorescein, SigmaAldricht) under simulated pulpar pressure $\left(20 \mathrm{~cm} \mathrm{H}_{2} \mathrm{O}\right)$ for $3 \mathrm{~h}[34,35]$. Then, the teeth were rinsed in ultrasonic bath for $60 \mathrm{~s}$, and sectioned into six $0.4 \mathrm{~mm}$ mesio-distal slabs using a slow-speed water-cooled diamond wafering blade. Both sides of the resin-dentin slabs were slightly polished using 1200-grit SiC paper for $30 \mathrm{~s}$ followed by ultrasonic bath for $60 \mathrm{~s}$. The bonded interfaces of all slabs were completely 
Table 1 - Adhesive systems, main components, bonding protocols and mode of application.

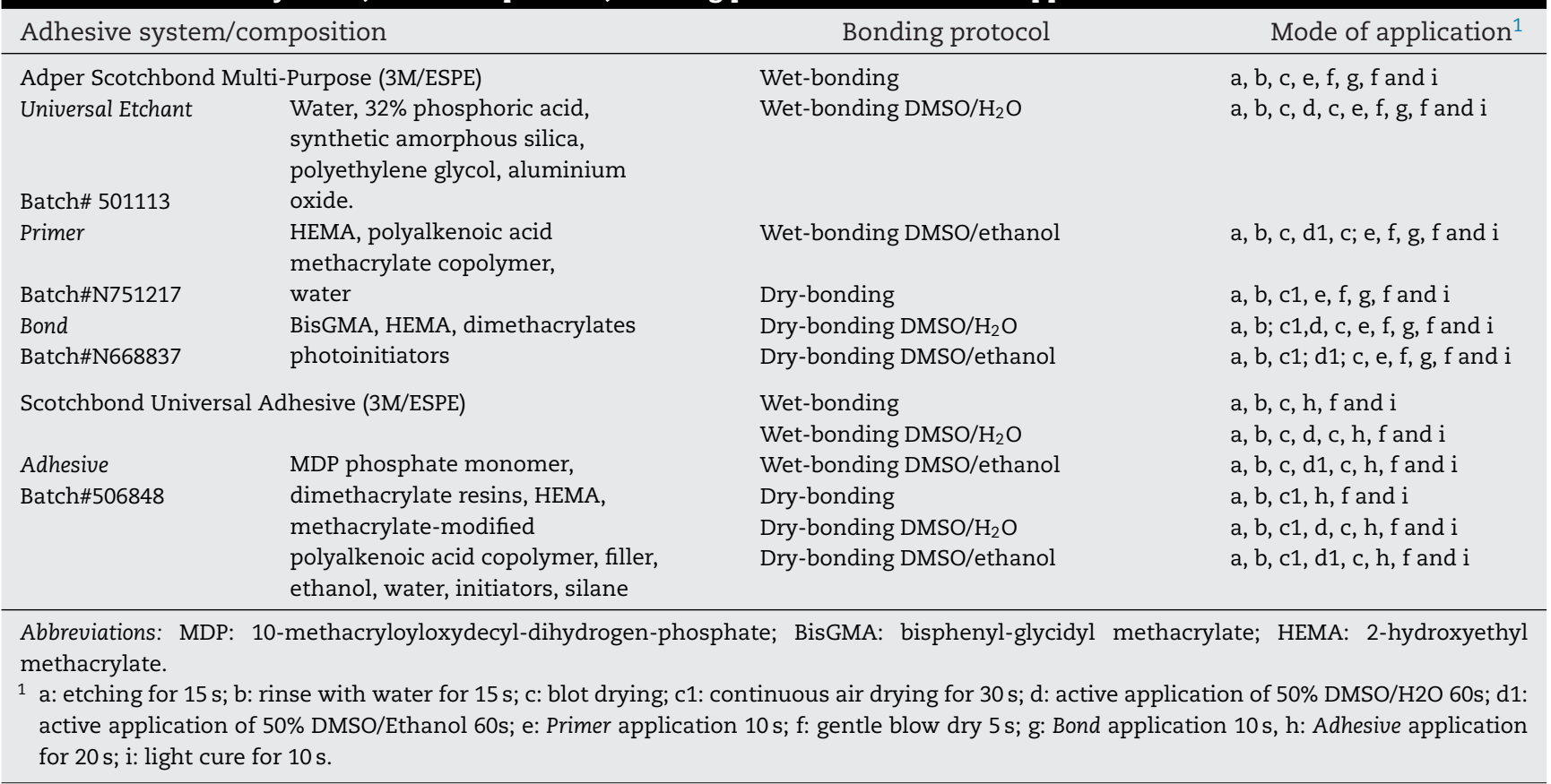

investigated and representative images of the most common patterns of micropermeability were randomly recorded. Two experienced blinded examiners evaluated all slabs. The imaging procedures were performed using a confocal laser scanning microscope (Leica SP5 TCS-CLSM, Leica Microsystems) equipped with a $63 \times 1.4$ NA oil immersion lens using $488 \mathrm{~nm}$ Argon and a $633 \mathrm{~nm}$ Helium-Neon ion laser illumination. CLSM fluorescence images were obtained from $20 \mu \mathrm{m}$ optical sections using a $0.5 \mu \mathrm{m}$ z-step, starting $1 \mu \mathrm{m}$ below the surface. The $z$-axis scans were compiled into a single and topographic projections using Leica SP5 CLSM image-processing software (Leica, Microsystems).

\subsection{Nanoleakage evaluation}

Two resin-dentin beams from each tooth ( $\mathrm{n}=8$ teeth/group) were randomly selected and submitted to nanoleakage evaluation according to a protocol previously described by Tay et al. [36]. Briefly, beams were placed in the ammoniacal silver nitrate in dark for $24 \mathrm{~h}$, rinsed thoroughly in distilled water and immersed in photo-developing solution for $8 \mathrm{~h}$ under fluorescent light to reduce silver ions to metallic silver grains within the nanosized water filled voids along the bonded interface. Resin-dentin beams were gently wet-polished using 600, 1000, 1200 and 4000-grit SiC paper followed by 6, 3, 1 and $0.25 \mu \mathrm{m}$ diamond pastes (Buehler) and ultrasonically cleaned for $5 \mathrm{~min}$ between polishing steps. Samples were dried in silica overnight and carbon coated (CA7625 Carbon Accessory, Quorum Technologies Ltd, United Kingdom). The bonded interfaces were analyzed in a scanning electron microscope (Phenom ProX, Phenom-World, Eindhoven, Netherlands) in backscattered electron mode. Magnifications ranging from $2500 \times$ to $6000 \times$ were used to qualitatively characterize the nanoleakage patterns. Sequential micrographs (2500× magnification) including the entire length of the adhesive interface were obtained from each resin-dentin beam. Silver nitrate uptake was quantitatively assessed using open-source image software (ImageJ, National Institute of Health, Bethesda, MD, USA) by a single-blinded examiner and the overall extension of silver uptake $(\mu \mathrm{m})$ for each group was converted into percentage values.

\subsection{Statistical analysis}

Nanoleakage and $\mu$ TBS data were evaluated separately. Tooth was considered the statistical unit. For the $\mu$ TBS data, the average value of a minimum of 8 beams per tooth was used for statistical analysis. The number of beams with premature failures were recorded and included as $0 \mathrm{MPa}$. Data from the $\mu$ TBS test were normally distributed (Kolmogorov-Smirnov Test, $p=0.200$ ) and homoscedastic (Levene Test, $p=0.529$ ). Three-way ANOVA was performed to evaluate the statistical interactions of the independent variables "adhesive system", "dentin moisture" and "dentin pretreatment". Microtensile bond strength (MPa) was considered the dependent variable. Statistical significance level was set in advance at $\alpha=0.05$. Post hoc multiple comparisons were performed with Tukey's studentized range (HSD) test. As the normality assumption of the nanoleakage data was violated, data was analyzed by Kruskal-Wallis followed by Dunn-Bonferroni multiple comparison test. Statistical significance was preset at $\alpha=0.05$ using SAS statistical software (SAS 9.4 Software, SAS Institute, NC, USA).

\section{Results}

\subsection{Microtensile bond strength}

Three-way ANOVA showed that the interactions between "adhesive system" * "dentin pretreatment" $(p<0.0001)$ and "adhesive system" * "dentin moisture" $(p=0.005)$ had signif- 
Table 2 - Microtensile bond strength values of wet- and dry-bonding protocols using DMSO/ $\mathrm{H}_{2} \mathrm{O}$ and DMSO/ethanol solutions as dentin pretreatments.

\begin{tabular}{|c|c|c|c|c|}
\hline & \multicolumn{2}{|c|}{ Scotchbond Multi-Purpose } & \multicolumn{2}{|c|}{ Scotchbond Universal } \\
\hline & Wet-bonding & Dry-bonding & Wet-bonding & Dry-bonding \\
\hline Control & $\begin{array}{l}30.13 \pm 4.99^{\mathrm{Ba}}[64-25 / 35 / 4] \\
(4.5 \%)\end{array}$ & $\begin{array}{l}17.53 \pm 2.81^{\mathrm{Bb}}[58-44 / 12 / 2] \\
(20.5 \%)\end{array}$ & $\begin{array}{l}27.46 \pm 4.01^{\mathrm{Aa}}[69-28 / 39 / 2] \\
(5.5 \%)\end{array}$ & $\begin{array}{l}27.58 \pm 4.55^{\mathrm{Aa}}[64-22 / 40 / 2] \\
(5.9 \%)\end{array}$ \\
\hline $\mathrm{DMSO} / \mathrm{H}_{2} \mathrm{O}$ & $\begin{array}{l}43.68 \pm 7.03^{\mathrm{Aa}}[64-21 / 38 / 5] \\
(3 \%)\end{array}$ & $\begin{array}{l}40.47 \pm 4.29^{\mathrm{Aa}}[67-24 / 35 / 8] \\
(4.3 \%)\end{array}$ & $\begin{array}{l}30.31 \pm 3.35^{\mathrm{Ab}}[64-23 / 36 / 5] \\
(7.2 \%)\end{array}$ & $\begin{array}{l}31.13 \pm 3.66^{\mathrm{Ab}}[67-22 / 42 / 3] \\
(6.9 \%)\end{array}$ \\
\hline DMSO/ethanol & $\begin{array}{l}42.86 \pm 5.87^{\mathrm{Aa}}[65-22 / 41 / 2] \\
(4.4 \%)\end{array}$ & $\begin{array}{l}41.80 \pm 4.73^{\mathrm{Aa}}[69-22 / 41 / 6] \\
(2.8 \%)\end{array}$ & $\begin{array}{l}32.91 \pm 3.29^{\mathrm{Ab}}[66-21 / 36 / 9] \\
(4.3 \%)\end{array}$ & $\begin{array}{l}31.78 \pm 5.61^{\mathrm{Ab}}[66-19 / 43 / 4] \\
(5.7 \%)\end{array}$ \\
\hline \multicolumn{5}{|c|}{$\begin{array}{l}\text { Dentin bond strength (MPa) means and standard deviation for all groups }(n=8) \text {. Similar superscripts capital letters indicate no significan } \\
\text { differences within each group (columns) and similar superscript lowercase letters indicate no significant differences between the groups with } \\
\text { the same treatment (rows) according to Tukey's studentized range (HSD) test }(p>0.05) \text {. The total number of tested resin-dentin beams and thei } \\
\text { failure modes for each group are expressed into brackets as [total number of tested beams-adhesive/mix/cohesive failures]. The percentage } \\
\text { of premature failures is indicated in parentheses. }\end{array}$} \\
\hline
\end{tabular}

icant effects on dentin bond strength. The triple interaction "dentin pretreatment" * "adhesive system" * "dentin moisture" ( $p=0.1)$ was not significant. The mean cross-sectional area of tested resin-dentin beams $\left(0.76 \mathrm{~mm}^{2} \pm 0.2\right)$ ranged from 0.71 to $0.84 \mathrm{~mm}^{2}$ with no significant differences between the groups $(p=0.64)$. Microtensile means $(\mathrm{MPa})$, standard deviations, pretest failures and fracture pattern distribution for all groups are reported in Table 2. Wet-bonding SBMP with DMSO/ $\mathrm{H}_{2} \mathrm{O}$ and DMSO/ethanol pretreatments provided significantly higher bond strengths $(p<0.05)$ compared to SBMP wet-bonding control group roughly by $45 \%$. Drybonding significantly reduced SBMP bond strength by over $40 \%$ $(p<0.05)$. However, when DMSO/ $\mathrm{H}_{2} \mathrm{O}$ and DMSO/ethanol pretreatments using SBMP were performed on dehydrated dentin, significantly two-fold higher bond strengths were obtained compared to the dry-bonding control group $(p<0.05)$, without significant differences between the DMSO-pretreatments. No significant differences in SBMP dentin bond strengths occurred when $\mathrm{DMSO} / \mathrm{H}_{2} \mathrm{O}$ or $\mathrm{DMSO} /$ ethanol treatments were used irrespective of dentin condition. No significant differences were observed between SBMP and SU when manufacturer's instructions using the wet-bonding technique were followed. Unlike SBMP, dry-bonding had no significant impact on SU bond strength. DMSO/ $\mathrm{H}_{2} \mathrm{O}$ and DMSO/ethanol pretreatments had no significant influence on SU bond strength irrespective of whether wet or dry-bonding approaches were used.

Mixed failure was the most common fracture pattern. Drybonding produced higher percentages of adhesive failures for SBMP compared to wet-bonding over $60 \%$, on top of producing a total of $20 \%$ pre-test failures. No substantial changes occurred when both DMSO pretreatments were used with SBMP under dry and wet conditions, producing similar failure modes to SBMP control. Dry-bonding had no impact on SU failure modes. Wet-bonding of SU with DMSO/ethanol produced $20 \%$ reduction in adhesive failures compared to control group; dry-bonding with $\mathrm{DMSO} / \mathrm{H}_{2} \mathrm{O}$ and DMSO/ethanol reduced approximately $20 \%$ and $30 \%$, respectively.

\subsection{Hybrid layer micropermeability evaluation using CLSM}

Representative CLSM images of resin-dentin interfaces are shown in Fig. 1. All samples presented some degree of flu- orescein penetration (i.e. micropermeability of water from the dentinal tubules) along the hybrid layer and/or around resin tags with differences in the extent of micropermeability levels in accordance with the bonding protocol used. SBMP wet-bonding (Fig. 1A) produced micropermeability sites throughout the entire bottom and lower half of the hybrid layer: fluorescein easily penetrated around resin tags extending throughout the hybrid layer thickness. Porous zones 3-4 $\mu \mathrm{m}$ wide immediately below the hybrid layer were identified. SU (Fig. 1C) produced a similar micropermeability pattern except that heavy fluorescein deposits around resin tags extending towards the hybrid layer were more evident. In general, wet-bonding of SU produced wider fluorescent bands below the hybrid layer depicting higher micropermeability compared to SBMP, irrespective of dentin pretreatment. While $\mathrm{DMSO} / \mathrm{H}_{2} \mathrm{O}$ had no considerable impact on micropermeability levels of wet-bonded SBMP (Fig. 1E), it reduced the extension of fluorescein deposits for SU in wet-bonding (Fig. 1G). Conversely, DMSO/ethanol markedly reduced fluorescent sites nearby the hybrid layer for wet-bonded SBMP and SU: for SBMP (Fig. 1I) fluorescein uptake was limited to minimal deposits sparsely located mostly around resin tags; while for SU (Fig. 1K), diffused-scattered fluorescent sites were observed.

Dry-bonding of SBMP (Fig. 1B) produced extensive fluorescein deposits throughout most of the hybrid layer and around resin tags forming wide fluorescent bands (roughly 7-10 $\mu \mathrm{m}$ ). Differently from SBMP, similar levels of fluorescein uptake in dry-bonded SU (Fig. 1D) and SU control group were evident, but with reduced fluorescein accumulation around dry-bonded resin tags. DMSO/ $\mathrm{H}_{2} \mathrm{O}$ (Fig. 1F) and DMSO/ethanol (Fig. 1J) pretreatments reduced micropermeability in drybonded SBMP samples, with the latter producing only sparse fluorescein deposits mainly around resin tags. For dry-bonded SU interfaces, both DMSO pretreatment solutions generally reduced the extension of fluorescein bands regardless of dentin moisture. Micropermeability levels for dry-bonded SU using DMSO/ $\mathrm{H}_{2} \mathrm{O}$ (Fig. $1 \mathrm{H}$ ) were lower than dry-bonded SU (Fig. 1D). DMSO/ $\mathrm{H}_{2} \mathrm{O}$ produced comparable results in both wet and dry dentin; however, DMSO/ethanol (Fig. 1L) reduced fluorescein deposition within the hybrid layer when SU was applied on dry dentin. Dry-bonding of SU with DMSO/ethanol produced thin fluorescent bands $(1-3 \mu \mathrm{m})$ several microns 
SCOTCHBOND MULTI-PURPOSE Wet-bonding
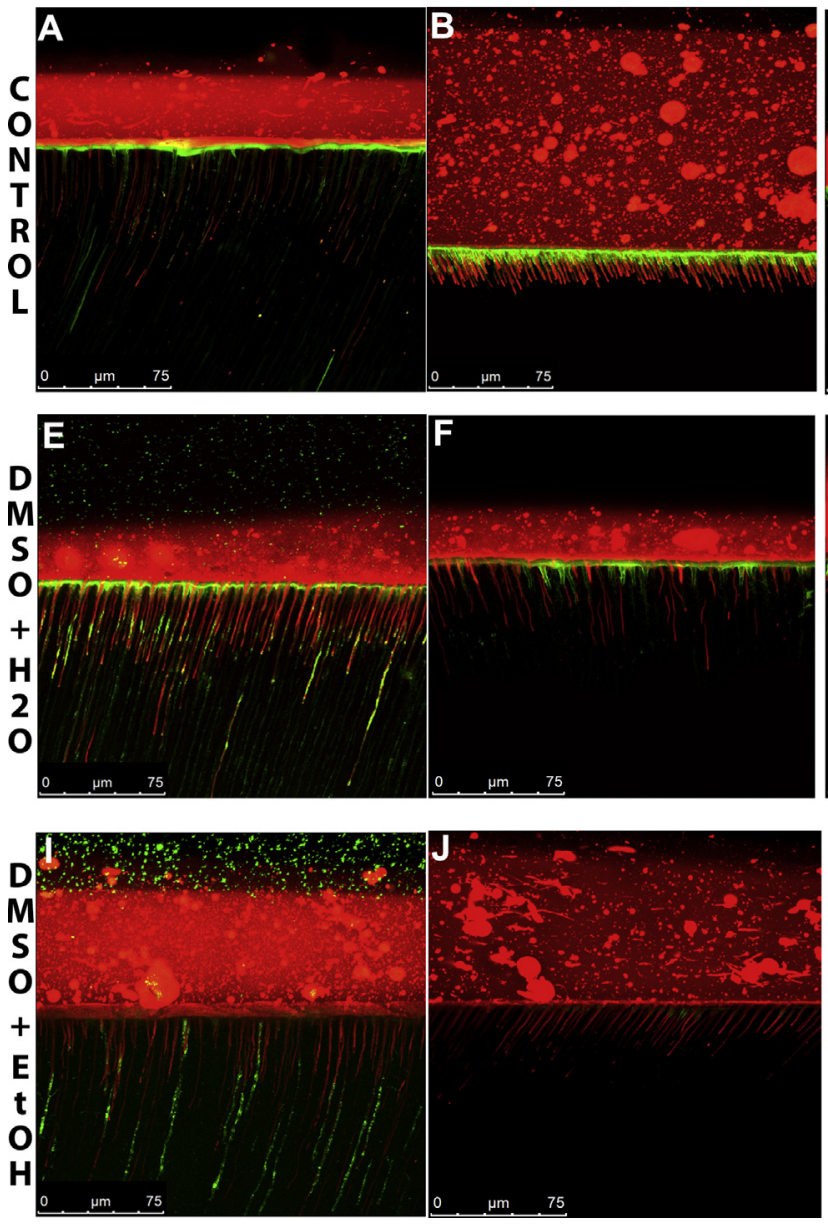

\section{SCOTCHBOND UNIVERSAL Wet-bonding Dry-bonding}
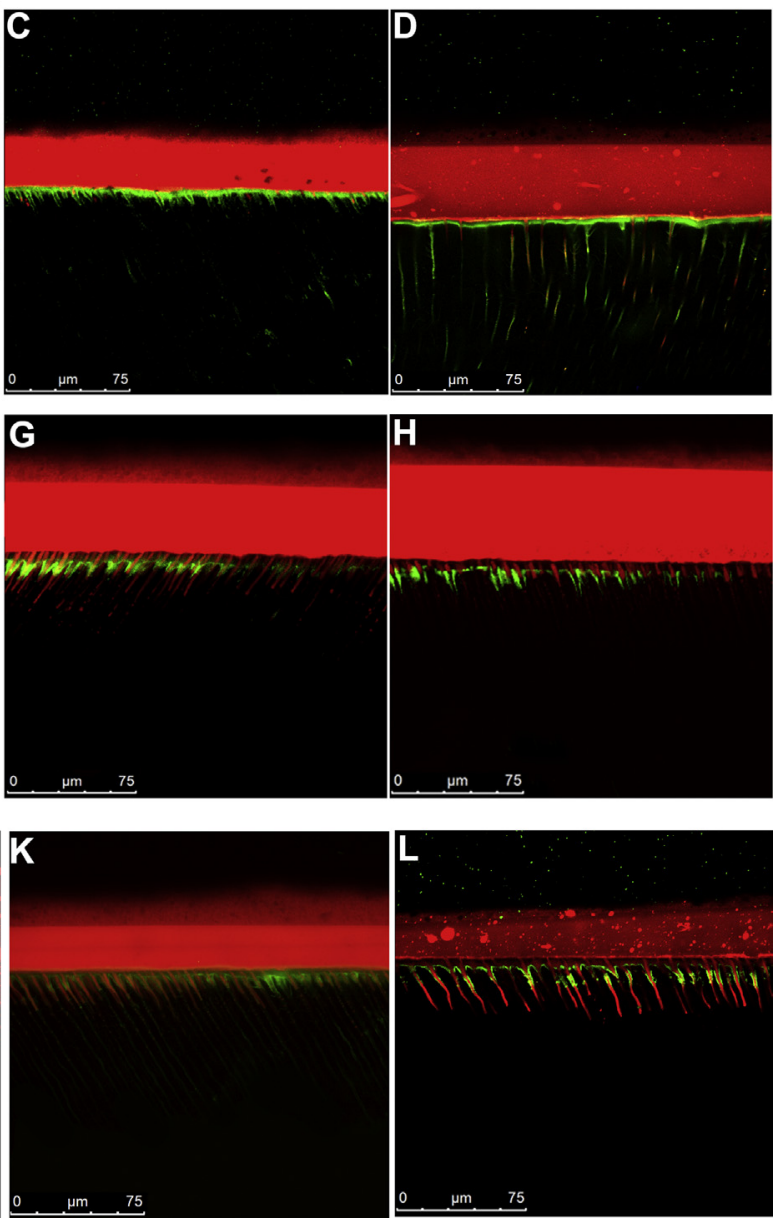

Fig. 1 - Representative micropermeability confocal laser scanning micrographs of DMSO-treated etched-dentin bonded with SBMP and SU following wet- and dry-bonding protocols. Sodium fluorescein under simulated pulpar pressure was used as a tracer solution to evaluate the dentin sealing ability of the proposed bonding protocols.

away from the hybrid layer. Nevertheless, dry-bonding of SU using DMSO/ $\mathrm{H}_{2} \mathrm{O}$ and $\mathrm{DMSO} /$ ethanol generally produced higher micropermeability levels compared to the respective dry-bonded SBMP groups.

\subsection{Nanoleakage evaluation}

Representative backscattered SEM micrographs showing the most common nanoleakage patterns/levels for all groups are presented in Fig. 2. The distributions of nanoleakage percentages along the hybrid layer for all groups are quantitatively shown in Fig. 3. All analyzed beams presented silver deposits within the resin-dentin interfaces. While wet-bonded SBMP presented few discontinuous areas of reticular silver deposits mostly located at the base of the hybrid layer (Fig. 2A), dry bonding produced a significant two-fold higher silver uptake composed mostly of dense reticular deposits along the entire extension of the bulk of hybrid layer (Fig. 2B). Regardless of dentin conditions (i.e. dry or wet) prior to bonding, pretreatment with $\mathrm{DMSO} / \mathrm{H}_{2} \mathrm{O}$ produced similar patterns nanoleakage levels (Fig. 2E and F) compared to SBMP control group (Fig. 2A) without significant differences in nanoleakage extension. Significantly lower silver uptake occurred when DMSO/ethanol pretreatments were performed on wet $(-54 \%)$, but especially on dry dentin (-71\%). High-magnification views of SBMP DMSO/ethanol specimens revealed the existence of isolated minor silver grains along the deepest part of the hybrid layer for both wet and dry bonding protocols (Fig. 2I and J). In general, SU presented significantly higher silver uptake when bonded to acid-etched dentin compared to SBMP. In SU wetbonding control group, spotted silver grains could be identified along most of the extension of the hybrid layer with few areas presenting reticular deposits (Fig. 2C). SU wet-bonded to $\mathrm{DMSO} / \mathrm{H}_{2} \mathrm{O}$ pretreated dentin also presented mostly a spotted pattern with sparse reticular silver deposits occupying most of the bulk of the hybrid layer without significant differences in silver uptake compared to SU wet-bonding control group. Significant lower extents of nanoleakage occurred on dry-bonding with $(-22 \%)$ and without DMSO/water $(-28 \%)$ compared to SU wet-bonding control group. Similar spotted patterns (Fig. 2H and D) to the SU wet-bonded group (Fig. 2C) were observed, but with reduced silver grain size and over- 


\section{SCOTCHBOND MULTI-PURPOSE} Wet-bonding
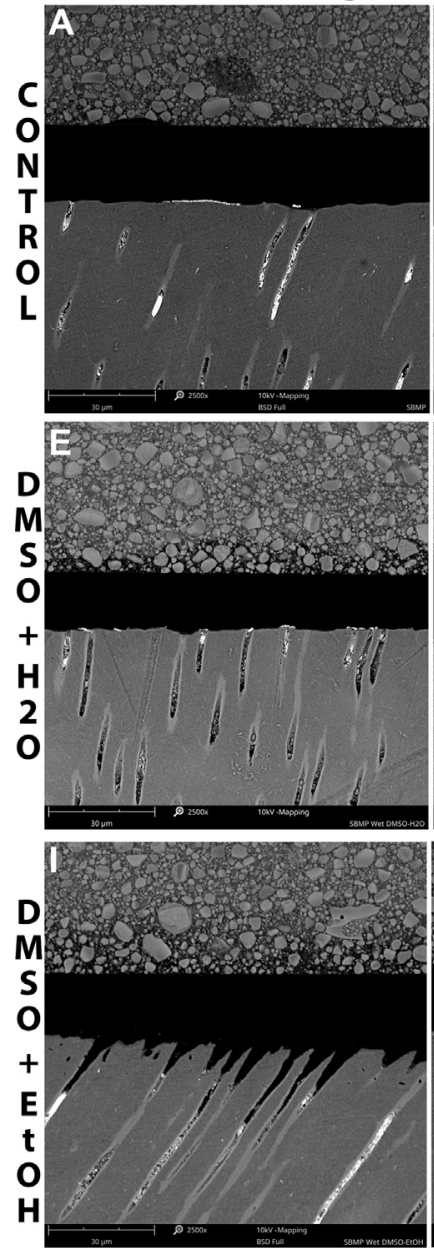

Dry-bonding
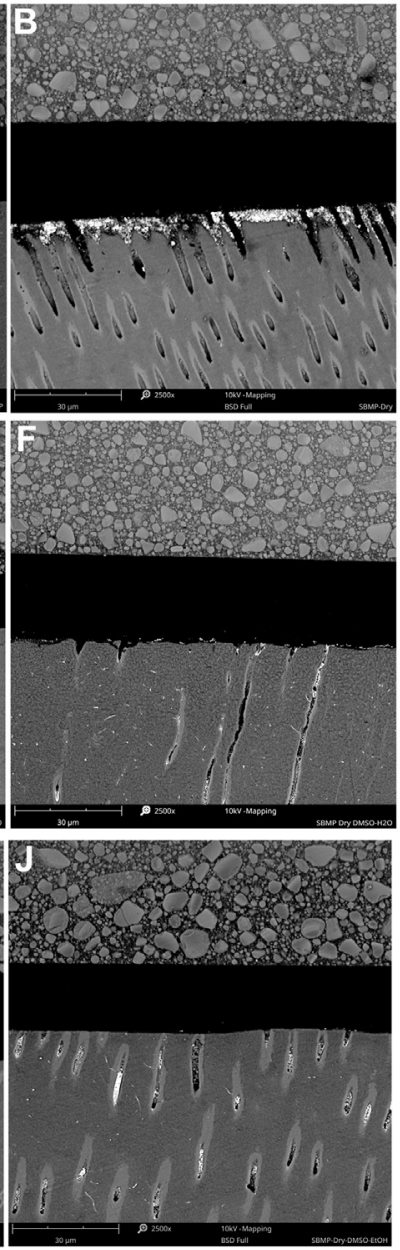

SCOTCHBOND UNIVERSAL Wet-bonding
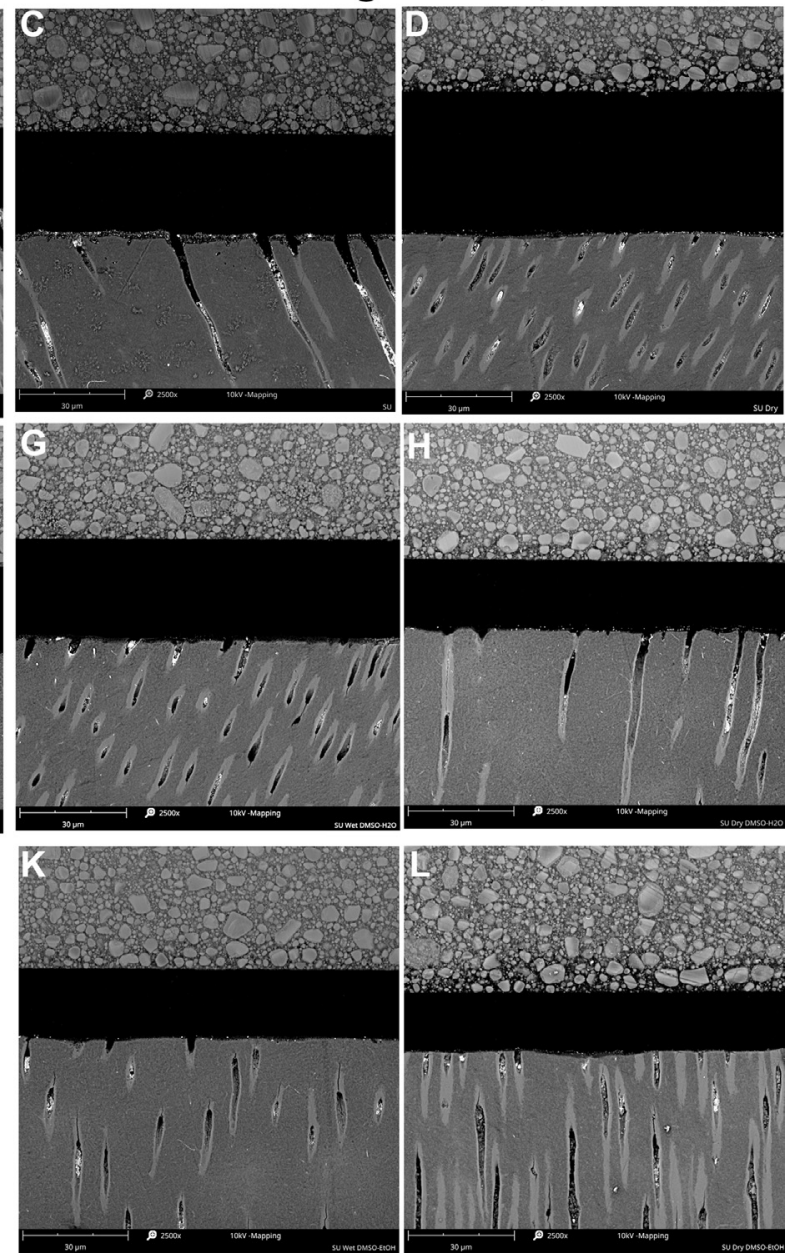

Fig. 2 - Representative nanoleakage backscattered SEM micrographs of DMSO-treated acid-etched dentin with SBMP and SU following wet- and dry-bonding protocols. Silver deposits within the hybrid layer depict the formation of porous water-filled interfaces.

all density. DMSO/ethanol pretreatment also produced sparse spotted silver deposits with significantly $30 \%$ lower nanoleakage expression compared to SU wet-bonding control group, irrespective of either wet- (Fig. 2K) or dry-bonding protocol (Fig. 2L).

\section{Discussion}

Since the interactions between the tested "dentin pretreatments" containing DMSO and "dentin moisture" $(p=0.005)$ had a significant impact on dentin bond strength, the first null hypothesis was rejected. In this context, the effects of "dentin pretreatment" and "dentin moisture" on dentin bond strength were adhesive-dependent. Both DMSO/ $\mathrm{H}_{2} \mathrm{O}$ and DMSO/ethanol pretreatments produced higher bond strengths irrespective of whether dry- or wet-bonding were performed when the multi-step etch-and-rinse adhesive was used. The mechanism in which DMSO-pretreatments affect dentin bonding is still not yet fully understood. However, DMSO improves adhesive infiltration into demineralized dentin [8] most likely due to biomodification of the collagen matrix as a result of: (i) increased spacing between the collagen microfibrils [22,25]; (ii) improvement in dentin wettability [28]; (iii) reduction in water's self-associative tendency [26]; and (iv) DMSO's ability to act as a penetration enhancer [24]. Therefore, DMSO/ $\mathrm{H}_{2} \mathrm{O}$ dentin pretreatment improved the monomer-dentin interaction contributing to enhanced bond strengths as previously presented [8].

The ability to bond relatively hydrophobic adhesives to dry demineralized collagen matrix in a clinically relevant time frame is somewhat controversial. According to Raoult's law, removal of excess water by evaporation before it has been mixed with solvated monomers allows rapid residual water removal $[37,38]$. Hydrogen bonding between water and monomers hinders effective water removal by evaporation [37]. For this reason, the dry-bonding approach used with etchand-rinse adhesives to eliminate water before hybridization has regained attention as an efficient method to reduce water affinity of resin-dentin bonds [14,39-41]. The main limitation is that chemical or physical dehydration of demineralized 


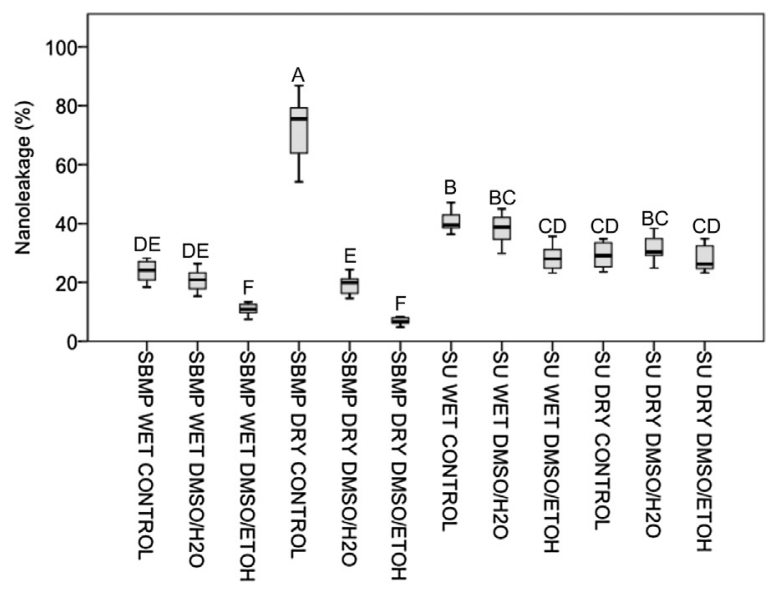

Fig. 3 - Boxplot of nanoleakage extension (\%) within the hybrid layer of wet- and dry-dentin samples $(n=8)$ bonded with SBMP and SU using DMSO solvated in either water (DMSO/ $\mathrm{H}_{2} \mathrm{O}$ ) or ethanol (DMSO/EtOH) as pretreatments. The box contains $50 \%$ of the data and the middle line of the box represents the median nanoleakage percentage distribution. The whiskers extend between the minimum and maximum value measured. Different capital letters indicate significant differences in nanoleakage percentages according to Dunn-Bonferroni post-hoc test $(p<0.05)$.

dentin brings collagen fibrils into contact facilitating hydrogen bonding between polypeptide chains. This shrinkage phenomenon reduces collagen interfibrillar spaces that serve as diffusion channels for resin infiltration. If the air-dried shrunk collagen matrix is not re-expanded before adhesive application, bonding to dry dentin can be severely jeopardized $[13,14]$. This is in agreement with the present results showing that in general dry-bonding of etch-and-rinse adhesives produce lower microtensile values compared to conventional wet-bonding. Previous attempts to enable dry-bonding of etch-and-rinse adhesives to demineralized dentin (e.g. vigorous adhesive application) produced at best comparable bond strengths to the conventional wet-bonding protocol $[40,42]$. Nevertheless, the collapse of dried collagen matrix caused by air-drying can be reversible $[13,40]$ as previously reported with the use of DMSO-water solutions [28] in a concentration dependent manner. Hoy's solubility parameters of the tested pretreatment solutions (Table 3) and their interaction with wet or dry collagen provide a plausible insight to stablish the ability of treatment solution re-expand collapsed collagen [13]. To re-expand dried collagen allowing proper adhesive penetration, interpeptide hydrogen bonding (hydrogen bonding force $\left.\left(\delta_{\mathrm{h}}\right) 14.8\left(\mathrm{~J} / \mathrm{cm}^{3}\right)^{1 / 2}\right)$ must be broken [13]. 50\% DMSO $/ \mathrm{H}_{2} \mathrm{O}\left(\delta_{\mathrm{h}} 26.8\right)$ and $50 \% \mathrm{DMSO} / \mathrm{ethanol}\left(\delta_{\mathrm{h}} 16.6\right)$ dentin pretreatments actively applied for $60 \mathrm{~s}$ acted as re-expanding solutions with higher $\delta_{\mathrm{h}}$ than air-dried collagen and thus were likely able to break such hydrogen bonds resulting with matrix re-expansion [13]. Even though the maximal expansion of dried dentin organic matrix using $50 \% \mathrm{DMSO} / \mathrm{H}_{2} \mathrm{O}$ is lower than pure water, the overall re-expansion of collapsed collagen is around $70 \%$ [28]. In the present study, higher dentin bond strengths were obtained for SBMP when air-dried dentin
Table 3 - Hoy's solubility parameters of common solvents used in adhesive dentistry including their mixtures for the tested pretreatment solutions $(\mathrm{v} / \mathrm{v})$, monomers and collagen in different conditions.

\begin{tabular}{|c|c|c|c|c|}
\hline Substance & $\delta_{\mathrm{d}}$ & $\delta_{\mathrm{p}}$ & $\delta_{\mathrm{h}}$ & $\delta_{\mathrm{t}}$ \\
\hline Water & 12.2 & 22.8 & 40.4 & 48.0 \\
\hline Ethanol & 12.6 & 11.2 & 20.0 & 26.1 \\
\hline DMSO & 13.1 & 16.2 & 13.1 & 24.6 \\
\hline $50 \% \mathrm{DMSO} / \mathrm{H}_{2} \mathrm{O}$ & 12.6 & 19.4 & 26.8 & 35.4 \\
\hline $50 \%$ DMSO/ethanol & 12.8 & 13.7 & 16.6 & 25.0 \\
\hline BisGMA & 16.6 & 13.4 & 5.8 & 22.1 \\
\hline HEMA & 13.3 & 12.3 & 15.2 & 23.6 \\
\hline Wet collagen & 11.8 & 15.3 & 22.5 & 30.1 \\
\hline Dry collagen & 11.7 & 12.1 & 14.8 & 22.5 \\
\hline
\end{tabular}

Values are in $\left(\mathrm{J} / \mathrm{cm}^{3}\right)^{1 / 2} . \delta_{\mathrm{d}}$-Hoy's solubility parameter for dispersive forces; $\delta_{\mathrm{p}}$-Hoy's solubility parameter for polar forces; $\delta_{\mathrm{h}}$-Hoy's solubility parameter for hydrogen bonding forces; $\delta_{\mathrm{t}}$-Hoy's total solubility parameter.

was pretreated by either one of the DMSO solutions. Biomodification of the collagen matrix [8,22] by DMSO pretreatments containing either water or ethanol improved multi-step etchand-rinse adhesives' bond effectiveness [8] irrespective of dentin moisture. Increased and faster dentin wettability with a fairly modest re-expansion ratio of collapsed collagen [28] may explain the higher bond strengths. To the best of our knowledge, production of higher immediate bond strengths on completely air-dried dentin compared to the conventional wet-bonding has not been previously presented.

In this new proposed bonding approach, application of DMSO/ethanol pretreatment-solution for $60 \mathrm{~s}$ on either wet or dry dentin produced higher bond strengths than the conventional wet-bonding protocol when SBMP was used. When the amphiphilic DMSO/ethanol pretreatment was performed on wet dentin, ethanol dehydrated the collagen matrix to some extent contributing to water removal. However, the presence of remaining DMSO (vapor pressure $0.6 \mathrm{mmHg}$ at $25^{\circ} \mathrm{C}$ ) most likely changed the residual water behavior due to DMSO's ability to break water self-associative tendency and displace water molecules [26]. In this sense, the mechanism involved in the DMSO/ethanol wet-bonding protocol aggregates water displacement when compared to the original ethanol-wet bonding technique, certainly making water replacement/displacement more effective in a relatively short application period. In addition, DMSO competes with water molecules in collagen interpeptide hydrogen bonding [26] and increases collagen interfibrillar spacing [25]. The triple-helical collagen molecules are covered with bound water [43], which limits the interaction of hydrophobic crosslinking monomers with collagen. The oxygen atom in DMSO hydrogen bonds with two [26] or three [44] water molecules, while the methyl groups form a hydrophobic end displacing water from demineralized collagen matrix [28]. Therefore, DMSO may disrupt this layer of water and improve the interaction between collagen and hydrophobic monomers irrespective of the vehicle used in the pretreatment solutions. Indeed, DMSO improves resin infiltration [8] and bond strength [8,22], as shown also in this study. 
SU is a universal etch-and-rinse adhesive containing ethanol and silane in addition to water having part of the original dimethacrylate monomers substituted by the functional monomer 10-methacryloyloxydecyl dihydrogen phosphate (10-MDP). This invariably reduces the overall availability of hydrophobic dimetacrylates crosslinking monomers. Although adhesives with higher crosslinking rates present improved mechanical properties [45], no significant differences in dentin bond strength were observed between SBMP and SU wet-bonded control groups. This is supported by previous findings [46] suggesting that universal adhesives should not perform differently from previous generations of etchand-rinse adhesives, at least in immediate conditions. Unlike SBMP, dry-bonding did not reduce SU bond strength which is in accordance with previous studies $[47,48]$. The longer application time of SU (10 s for SBMP vs. 20 s for SU) apparently produced re-expansion of collagen fibrils by the water present in the adhesive composition producing similar immediate bond strengths to wet-bonded samples. Even though SBMP presented higher bond strengths irrespective of dentin moisture for both pretreatments, DMSO pretreatments had no significant effect on immediate bond strength of SU. Similarly, it has been reported that the immediate bond strength of a simplified etch-and-rinse adhesive was not affected by the same DMSO/ $\mathrm{H}_{2} \mathrm{O}$ pretreatment [31]. Normally, diffusion of high molecular weight monomers across the extension of demineralized dentin is deficient [49]. For instance, the absolute molar concentration of BisGMA at the middle of the hybrid layer is only about $10 \%$ of the expected concentrations in an ideally infiltrated hybrid layer [50]. Since DMSO is an effective penetration enhancer [24], it possibly improved BisGMA diffusion across the hybrid layer contributing to polymer chain crosslinking contributing to higher bond strengths for SBMP. Due to reduced availability of crosslinking dimetacrylates monomers in SU, solely favoring their penetration with DMSO limited the improvement of bond strength to the same extent as in SBMP. Reduction of flexible poly-HEMA gel formation in deeper portions of the hybrid layer $[49,51]$ was most likely not as efficient which might explain similar bond strengths in SU treated and untreated groups. More studies using Raman spectroscopy and nanoindentation should be performed to evaluate the monomer composition and mechanical properties of DMSO-treated hybrid layer.

The presence of excess water during dentin hybridization increases the formation of hydrogels at the HEMA-rich lower half of hybrid layer $[49,50]$ resulting in water permeable resin-dentin interfaces. Silver [36] and fluorescein [34,35] deposition on the bonded interface reflected the presence of such water-rich zones revealing inconsistent resin-infiltration of demineralized collagen in both adhesives. While nanoleakage analyses in SEM permits a precise interpretation with higher resolution images of the silver deposition within the microporosities at the hybrid layer, micropermeability provides an indication of the relative sealing of the bonded interface [52,53]. Moreover, using a water-based fluorescein tracer solution under simulated pulpar pressure and CLSM for micropermeability assessment allows direct fluid movement visualization with minimal specimen preparation reducing possible artifacts [53]. Since the extension of fluorescein and silver deposition along the bonded interface of SBMP and SU samples was affected by dentin moisture and the DMSO solutions used, the second null hypothesis was rejected. While dry-bonding severely compromised the sealing ability of SBMP, no negative effects were observed on SU. However, DMSO pretreatments reduced micropermeability and nanoleakage levels for both adhesives, reducing the extension of the porous water-rich poorly impregnated resin layer immediately below the hybrid layer even when dry-bonding was performed. The vehicle used for DMSO application also had an impact on micropermeability and nanoleakage levels: DMSO/ethanol pretreatment produced the lowest leakage levels irrespective of the adhesive used, especially in dry-bonding. Extensive air-drying followed by application of DMSO/ethanol solution invariably reduced the amount of water present at the hybrid layer and produced a favorable dentin bonding substrate. Therefore, the combination of residual water evaporation by extensive air drying and DMSO/ethanol pretreatment seems to be a highly promising method to reduce microporosities at the hybrid layer irrespective of dentin moisture condition.

\section{Conclusion}

This study presents compelling evidence that residual water removal from resin-dentin interfaces of simplified and threestep etch-and-rinse adhesives may be possible by air drying in a clinically realistic time frame without compromising - bonding effectiveness. Furthermore, $\mathrm{DMSO} / \mathrm{H}_{2} \mathrm{O}$ and DMSO/ethanol pretreatments on either dry or wet dentin improved resin-dentin interfaces by increasing SBMP bond strength and reducing overall nanoleakage and micropermeability levels of both SBMP and SU bonded interfaces. The proposed DMSO-pretreatments may have potential benefits on the etch-and-rinse bonding mechanism producing improved hybrid layers with reduced defective and vulnerable degradation sites irrespective of whether dry- or wet-bonding techniques are employed.

\section{Acknowledgments}

This work was supported by grant \#296653 from the Academy of Finland to AT-M (PI), EVO funding of Turku University Hospital to AT-M (PI).

\section{REF E R E N C E S}

[1] Pashley DH, Tay FR, Breschi L, Tjäderhane L, Carvalho RM, Carrilho M, et al. State of the art etch-and-rinse adhesives. Dent Mater 2011;27:1-16, http://dx.doi.org/10.1016/j.dental.2010.10.016.

[2] Tjäderhane L, Nascimento FD, Breschi L, Mazzoni A, Tersariol ILS, Geraldeli S, et al. Strategies to prevent hydrolytic degradation of the hybrid layer-a review. Dent Mater 2013;29:999-1011, http://dx.doi.org/10.1016/j.dental.2013.07.016.

[3] Van Meerbeek B, Yoshihara K, Yoshida Y, Mine A, De Munck J, Van Landuyt KL. State of the art of self-etch adhesives. Dent Mater 2011;27:17-28, http://dx.doi.org/10.1016/j.dental.2010.10.023. 
[4] van Dijken JWV, Pallesen U. Long-term dentin retention of etch-and-rinse and self-etch adhesives and a resin-modified glass ionomer cement in non-carious cervical lesions. Dent Mater 2008;24:915-22, http://dx.doi.org/10.1016/j.dental.2007.11.008.

[5] Van Dijken JWV. A prospective 8-year evaluation of a mild two-step self-etching adhesive and a heavily filled two-step etch-and-rinse system in non-carious cervical lesions. Dent Mater 2010;26:940-6, http://dx.doi.org/10.1016/j.dental.2010.05.009.

[6] van Dijken JWV, Sunnegårdh-Grönberg K, Lindberg A. Clinical long-term retention of etch-and-rinse and self-etch adhesive systems in non-carious cervical lesions. A 13 years evaluation. Dent Mater 2007;23:1101-7, http://dx.doi.org/10.1016/j.dental.2006.10.005.

[7] Frassetto A, Breschi L, Turco G, Marchesi G, Di Lenarda R, Tay FR, et al. Mechanisms of degradation of the hybrid layer in adhesive dentistry and therapeutic agents to improve bond durability-a literature review. Dent Mater 2015;32:e41-53, http://dx.doi.org/10.1016/j.dental.2015.11.007.

[8] Stape THS, Tjäderhane L, Marques MR, Aguiar FHB, Martins LRM. Effect of dimethyl sulfoxide wet-bonding technique on hybrid layer quality and dentin bond strength. Dent Mater 2015;31:676-83, http://dx.doi.org/10.1016/j.dental.2015.03.008.

[9] Spencer P, Wang Y, Katz JL. Identification of collagen encapsulation at the dentin/adhesive interface. J Adhes Dent 2004;6:91-5. Article.

[10] Tjäderhane L. Dentin bonding: can we make it last? Oper Dent 2015;40:4-18, http://dx.doi.org/10.2341/14-095-BL.

[11] Spencer P, Ye Q, Park J, Topp EM, Misra A, Wang Y, et al. Adhesive/dentin interface: the weak link in the composite restoration. Ann Biomed Eng 2011;38:1989-2003, http://dx.doi.org/10.1007/s10439-010-9969-6. Adhesive/Dentin.

[12] Liu Y, Tjäderhane L, Breschi L, Mazzoni A, Li N, Mao J, et al. Limitations in bonding to dentin and experimental strategies to prevent bond degradation. J Dent Res 2011;90:953-68, http://dx.doi.org/10.1177/0022034510391799.

[13] Pashley DH, Tay FR, Carvalho RM, Rueggeberg FA, Agee KA, Carrilho M, et al. From dry bonding to water-wet bonding to ethanol-wet bonding. A review of the interactions between dentin matrix and solvated resins using a macromodel of the hybrid layer. Am J Dent 2007;20:7-20.

[14] Manso AP, Marquezini L, Silva SMA, Pashley DH, Tay FR, Carvalho RM. Stability of wet versus dry bonding with different solvent-based adhesives. Dent Mater 2008;24:476-82, http://dx.doi.org/10.1016/j.dental.2007.04.009.

[15] Schulze KA, Oliveira SA, Wilson RS, Gansky SA, Marshall GW, Marshall SJ. Effect of hydration variability on hybrid layer properties of a self-etching versus an acid-etching system. Biomaterials 2005;26:1011-8, http://dx.doi.org/10.1016/j.biomaterials.2004.03.037.

[16] Hashimoto M, Tay FR, Svizero NR, de Gee AJ, Feilzer AJ, Sano $\mathrm{H}$, et al. The effects of common errors on sealing ability of total-etch adhesives. Dent Mater 2006;22:560-8, http://dx.doi.org/10.1016/j.dental.2005.06.004.

[17] Tay FR, Pashley DH, Kapur RR, Carrilho MRO, Hur YB, Garrett LV, et al. Bonding BisGMA to dentin-a proof of concept for hydrophobic dentin bonding. J Dent Res 2007;86:1034-9, http://dx.doi.org/10.1177/154405910708601103.

[18] Brackett MG, Li N, Brackett WW, Sword RJ, Qi YP, Niu LN, et al. The critical barrier to progress in dentine bonding with the etch-and-rinse technique. J Dent 2011;39:238-48, http://dx.doi.org/10.1016/j.jdent.2010.12.009.

[19] Ye Q Wang Y, Spencer P. Nanophase separation of polymers exposed to simulated bonding conditions. J Biomed Mater
Res B Appl Biomater 2009;88:339-48,

http://dx.doi.org/10.1002/jbm.b.31047.

[20] Hashimoto M, Ohno H, Kaga M, Endo K, Sano H, Oguchi H. In vivo degradation of resin-dentin bonds in humans over 1 to 3 years. J Dent Res 2000;79:1385-91.

[21] Hitmi L, Bouter D, Degrange M. Influence of drying and HEMA treatment on dentin wettability. Dent Mater 2002;18:503-11, http://dx.doi.org/10.1016/S0109-5641(01)00075-6.

[22] Tjäderhane L, Mehtälä P, Scaffa P, Vidal C, Pääkkönen V, Breschi L, et al. The effect of dimethyl sulfoxide (DMSO) on dentin bonding and nanoleakage of etch-and-rinse adhesives. Dent Mater 2013;29:1055-62, http://dx.doi.org/10.1016/j.dental.2013.07.014.

[23] Geurtsen W, Lehmann F, Spahl W, Leyhausen G. Cytotoxicity of 35 dental resin composite monomers/additives in permanent 3T3 and three human primary fibroblast cultures. J Biomed Mater Res 1998;41:474-80.

[24] Marren K. Dimethyl sulfoxide: an effective penetration enhancer for topical administration of NSAIDs. Phys Sport 2011;39:75-82, http://dx.doi.org/10.3810/psm.2011.09.1923.

[25] Zimmerley M, McClure RA, Choi B, Potma EO. Following dimethyl sulfoxide skin optical clearing dynamics with quantitative nonlinear multimodal microscopy. Appl Opt 2009;48:D79-87, http://dx.doi.org/10.1364/AO.48.000D79.

[26] Vishnyakov A, Lyubartsev AP, Laaksonen A. Molecular dynamics simulations of dimethyl sulfoxide and dimethyl sulfoxide-water mixture. J Phys Chem A 2001;105:1702-10, http://dx.doi.org/10.1021/jp0007336.

[27] Ekambaram M, Yiu CKY, Matinlinna JP. An overview of solvents in resin-dentin bonding. Int J Adhes Adhes 2015;57:22-33, http://dx.doi.org/10.1016/j.ijadhadh.2014.09.007.

[28] Mehtälä P, Pashley DH, Tjäderhane L. Effect of dimethyl sulfoxide on dentin collagen. Dent Mater 2017;33:915-22, http://dx.doi.org/10.1016/j.dental.2017.04.018.

[29] Stape THS, Tjäderhane L, Tezvergil-Mutluay A, Yanikian CRF, Szesz AL, Loguercio AD, et al. Dentin bond optimization using the dimethyl sulfoxide-wet bonding strategy: a 2-year in vitro study. Dent Mater 2016;32:1472-81, http://dx.doi.org/10.1016/j.dental.2016.09.015.

[30] Stape THS, Tjäderhane L, Marques MR, Aguiar FHB, Martins LRM. Effect of dimethyl sulfoxide wet-bonding technique on hybrid layer quality and dentin bond strength. Dent Mater 2015;31:676-83, http://dx.doi.org/10.1016/j.dental.2015.03.008.

[31] Guo J, Lei W, Yang H, Zhang Y, Zhao S, Huang C. Dimethyl sulfoxide wet-bonding technique may improve the quality of dentin bonding. J Adhes Dent 2017:229-37, http://dx.doi.org/10.3290/j.jad.a38438.

[32] Reis A, de Carvalho Cardoso P, Vieira LCC, Baratieri LN, Grande RHM, Loguercio AD. Effect of prolonged application times on the durability of resin-dentin bonds. Dent Mater 2008;24:639-44, http://dx.doi.org/10.1016/j.dental.2007.06.027.

[33] Shono Y, Ogawa T, Terashita M, Brewer P, Carvalho R, Pashley E, et al. Regional measurement of resin-dentin bonding as an array. Am Chem Soc Polym Prepr Div Polym Chem 1997;38:135-6, http://dx.doi.org/10.1177/00220345990780021001.

[34] Sauro S, Osorio R, Watson TF, Toledano M. Assessment of the quality of resin-dentin bonded interfaces: an AFM nano-indentation, mirotBS and confocal ultramorphology study. Dent Mater 2012;28:622-31, http://dx.doi.org/10.1016/j.dental.2012.02.005.

[35] Sauro S, Watson TF, Mannocci F, Miyake K, Huffman BP, Tay FR, et al. Two-photon laser confocal microscopy of micropermeability of resin-dentin bonds made with water 
or ethanol wet bonding. J Biomed Mater Res B Appl Biomater 2009;90 B:327-37, http://dx.doi.org/10.1002/jbm.b.31290.

[36] Tay FR, Pashley DH, Yoshiyama M. Two modes of nanoleakage expression in single-step adhesives. J Dent Res 2002;81:472-6, http://dx.doi.org/10.1177/154405910208100708.

[37] Yiu CKY, Pashley EL, Hiraishi N, King NM, Goracci C, Ferrari $\mathrm{M}$, et al. Solvent and water retention in dental adhesive blends after evaporation. Biomaterials 2005;26:6863-72, http://dx.doi.org/10.1016/j.biomaterials.2005.05.011.

[38] Pashley EL, Zhang Y, Lockwood PE, Rueggeberg FA, Pashley DH. Effects of HEMA on water evaporation from water-HEMA mixtures. Dent Mater 1998;14:6-10.

[39] Zhou J, Chiba A, Scheffel DLS, Hebling J, Agee K, Tagami J, et al. Cross-linked dry bonding: a new etch-and-rinse technique. Dent Mater 2016;32:1124-32, http://dx.doi.org/10.1016/j.dental.2016.06.014.

[40] Dal-Bianco K, Pellizzaro A, Patzlaft R, de Oliveira Bauer JR, Loguercio AD, Reis A. Effects of moisture degree and rubbing action on the immediate resin-dentin bond strength. Dent Mater 2006;22:1150-6, http://dx.doi.org/10.1016/j.dental.2005.10.010.

[41] Reis A, Pellizzaro A, Dal-Bianco K, Gones OM, Patzlaff $R$, Loguercio AD. Impact of adhesive application to wet and dry dentin on long-term resin-dentin bond strengths. Oper Dent 2007;32:380-7, http://dx.doi.org/10.2341/06-107.

[42] Loguercio AD, Loeblein F, Cherobin T, Ogliari F, Piva E, Reis A. Effect of solvent removal on adhesive properties of simplified etch-and-rinse systems and on bond strengths to dry and wet dentin. J Adhes Dent 2009;11:213-9, http://dx.doi.org/10.3290/j.jad.a15627.

[43] Agee KA, Prakki A, Abu-Haimed T, Naguib GH, Nawareg MA, Tezvergil-Mutluay A, et al. Water distribution in dentin matrices: bound vs. unbound water. Dent Mater 2015;31:205-16, http://dx.doi.org/10.1016/j.dental.2014.12.007.

[44] Kiefer J, Noack K, Kirchner B. Hydrogen bonding in mixtures of dimethyl sulfoxide and cosolvents. Curr Phys Chem
2011;1:340-51,

http://dx.doi.org/10.2174/1877947611101040340.

[45] Ye Q, Spencer P, Wang Y, Misra A. Relationship of solvent to the photopolymerization process, properties, structure in model dentin adhesives. J Biomed Mater Res A 2007;80:342-50, http://dx.doi.org/10.1002/jbm.a.30890.

[46] Chen C, Niu L-N, Xie H, Zhang Z-Y, Zhou L-Q, Jiao K, et al. Bonding of universal adhesives to dentine-old wine in new bottles? J Dent 2015;43:525-36, http://dx.doi.org/10.1016/j.jdent.2015.03.004.

[47] Marchesi G, Frassetto A, Mazzoni A, Apolonio F, Diolosà M, Cadenaro $\mathrm{M}$, et al. Adhesive performance of a multi-mode adhesive system: 1-year in vitro study. J Dent 2014;42:603-12, http://dx.doi.org/10.1016/j.jdent.2013.12.008.

[48] Perdigão J, Loguercio D. Universal or multi-mode adhesives: why and how? J Adhes Dent 2014;16:193-4, http://dx.doi.org/10.3290/j.jad.a31871.

[49] Zou Y, Jessop JLP, Armstrong SR. In vitro enzymatic biodegradation of adhesive resin in the hybrid layer. J Biomed Mater Res A 2010;94:187-92, http://dx.doi.org/10.1002/jbm.a.32689.

[50] Zou Y, Armstrong SR, Jessop JLP. Quantitative analysis of adhesive resin in the hybrid layer using raman spectroscopy. J Biomed Mater Res A 2010;94:288-97, http://dx.doi.org/10.1002/jbm.a.32692.

[51] Wang Y, Spencer P, Walker MP. Chemical profile of adhesive/caries-affected dentin interfaces using Raman microspectroscopy. J Biomed Mater Res A 2007;81:279-86, http://dx.doi.org/10.1002/jbm.a.30981.

[52] Sidhu SK, Watson TE. Interfacial characteristics of resin-modified glass-ionomer materials: a study on fluid permeability using confocal fluorescence microscopy. J Dent Res 1998;77:1749-59, http://dx.doi.org/10.1177/00220345980770091101.

[53] $\bar{D}$ 'Alpino PHP, Pereira JC, Svizero NR, Rueggeberg FA, Pashley DH. Use of fluorescent compounds in assessing bonded resin-based restorations: a literature review. J Dent 2006;34:623-34, http://dx.doi.org/10.1016/j.jdent.2005.12.004. 